\title{
Assessment of Functional Phosphatidylinositol 3-Kinase Pathway Activity in Cancer Tissue Using Forkhead Box- 0 Target Gene Expression in a Knowledge-Based Computational Model
}

Henk van Ooijen, ${ }^{*}$ Marten Hornsveld, ${ }^{\dagger}$ Christa Dam-de Veen, ${ }^{*}$ Rick Velter, ${ }^{*}$ Meng Dou, ${ }^{*}$ Wim Verhaegh, ${ }^{*}$ Boudewijn Burgering, and Anja van de Stolpe*

From Philips Research, * Eindhoven; and the University Medical Center Utrecht ${ }^{\dagger}{ }^{*}$ trecht, the Netherlands

Accepted for publication

May 22, 2018.

Address correspondence to Anja van de Stolpe, M.D., Ph.D., Philips Research, High Tech Campus 11, Eindhoven, the Netherlands. E-mail: anja van.de.stolpe@philips.com.

\begin{abstract}
The phosphatidylinositol 3-kinase (PI3K) pathway is commonly activated in cancer. Tumors are potentially sensitive to $\mathrm{PI} 3 \mathrm{~K}$ pathway inhibitors, but reliable diagnostic tests that assess functional PI3K activity are lacking. Because PI3K pathway activity negatively regulates forkhead box-0 (FOXO) transcription factor activity, FOXO target gene expression is inversely correlated with PI3K activity. A knowledge-based Bayesian computational model was developed to infer PI3K activity in cancer tissue samples from FOXO target gene mRNA levels and validated in cancer cell lines treated with PI3K inhibitors. However, applied to patient tissue samples, FOXO was often active in cancer types with expected active PI3K. SOD2 was differentially expressed between FOXO-active healthy and cancer tissue samples, indicating that cancer-associated cellular oxidative stress alternatively activated FOXO. To enable correct interpretation of active FOXO in cancer tissue, threshold levels for normal SOD2 expression in healthy tissue were defined above which FOXO activity is oxidative stress induced and below which PI3K regulated. In slow-growing luminal $\mathrm{A}$ breast cancer and low Gleason score prostate cancer, FOXO was active in a PI3K-regulated manner, indicating inactive PI3K. In aggressive luminal B, HER2, and basal breast cancer, FOXO was increasingly inactive or actively induced by oxidative stress, indicating PI3K activity. We provide a decision tree that facilitates functional PI3K pathway activity assessment in tissue samples from patients with cancer for therapy response prediction and prognosis. (Am J Pathol 2018, 188: 1956-1972; https://doi.org/10.1016/j.ajpath.2018.05.020)
\end{abstract}

In the past decade, systemic treatment of cancer moved from conventional chemotherapy toward administration of drugs that target tumor traits chosen on an individual patient basis. This precision medicine approach requires biomarkers that reliably predict response to targeted drugs. ${ }^{1}$ Cancer growth and metastasis are driven by roughly 10 to 12 cellular signal transduction pathways, relatively independent of the cancer cell type of origin. ${ }^{2-4}$ The phosphatidylinositol 3-kinase (PI3K) pathway is one of the main cellular growth factor signaling pathways frequently hyperactivated in cancer. ${ }^{2}$

The PI3K pathway inhibitors are used in cancer treatment alone or in combinations with other targeted strategies or conventional chemotherapy. ${ }^{5-7}$ Despite selection of potentially responsive patients based on PI3K pathway mutation analysis, only a subpopulation of patients respond adequately to the drugs. ${ }^{8,9}$ To improve prediction of drug

Supported by Cancer genomics Nederland (M.H. and B.B.) and Royal Philips funding for the Pathway Diagnostics Research program within Philips Research.

H.v.O. and M.H. contributed equally to this work.

B.B. and A.v.d.S. contributed equally to this work as senior authors.

Disclosures: H.v.O., C.D.-d.V., R.V., M.D., W.V., and A.v.d.S. are employed by Philips Research and received company funding for the Pathway Diagnostics Research program within Philips Research; M.H. and B.B. received funding from Cancer Genomics Nederland.

Current address of M.H., Leiden University Medical Center, The Oncode Institute, Leiden, the Netherlands; of B.B., The Oncode Institute, Utrecht, the Netherlands. 
response and monitor therapy efficacy or emerging resistance, tests that measure functional PI3K activity are needed.

We have previously described a knowledge-based computational approach to assess signal transduction pathway activity in cancer tissue samples based on measuring target gene mRNA levels of the pathway-specific transcription factor. ${ }^{10,11} \mathrm{We}$ report development of an mRNA-based assay for quantitative measurement of PI3K pathway activity that uses forkhead box-O (FOXO) transcription factor-induced RNA transcription as readout based on the well-known inverse association between FOXO and PI3K pathway activity. ${ }^{12-16}$ The model was biologically validated, using breast and lung cancer cell lines treated with PI3K pathway inhibitors or carrying doxycycline-inducible active FOXO3 constructs.

In cancer tissue, FOXO can be alternatively activated by cellular oxidative stress, a common trait in cancer that interferes with the inverse association with PI3K pathway activity. The level of SOD2/MnSOD, a FOXO target gene, was used to distinguish between the two functional states of FOXO activity, resulting in a robust approach to assess PI3K pathway activity in individual patient cancer samples.

\section{Materials and Methods}

\section{Cell Culture-Based Model System for F0X03 Activity}

MCF7 and MDA-MB-231 breast cancer cell lines were cultured in Dulbecco's modified Eagle's medium F12 that contained 10\% fetal bovine serum (FBS) (Lonza Group, Basel, Switzerland), $100 \mathrm{U} / \mathrm{mL}$ of penicillin, and $100 \mu \mathrm{g} / \mathrm{mL}$ of streptomycin (Lonza Group). Transfecting thirdgeneration packaging vectors using polyethylenimine into HEK293T cells generated lentiviral particles. ${ }^{17}$ MCF7 and MDA-MB-231 cells were stably transduced with lentivirus that contained pINDUCER20-FOXO3.A3, allowing doxycycline-induced expression of constitutively active FOXO3 (FOXO3.A3). ${ }^{13,18,19}$ Cells were treated with $20 \%$ FBS or $10 \mu \mathrm{mol} / \mathrm{L}$ of the PI3K inhibitor LY294002 (Selleckchem, Houston, TX) for 16 hours to activate and inactivate the endogenous PI3K pathway, respectively. FOXO3.A3 expression was induced by 16 hours treatment with $10 \mathrm{ng} / \mathrm{mL}$ of doxycycline.

\section{RNA Isolation and Affymetrix Microarray Hybridization}

Treated cells were harvested after 16 hours of the respective incubations as indicated; RNA was isolated using the RNeasy kit (Qiagen, Hilden, Germany) and hybridized on Affymetrix HT HG-U133+PM Array Plate by ServiceXS (GenomeScan BV, Leiden, the Netherlands) and AROS (Eurofins, Aarhus, Denmark). Affymetrix data are available in the Gene Expression Omnibus (GEO) database (https://www.ncbi.nlm.nih.gov/geo; accession number GSE113479).
Microarray Data Processing and Quality Control on Affymetrix Microarray Data

All microarrays that were used were from Affymetrix HG-U133Plus2.0 or Affymetrix HG-U133+PM microarrays (Supplemental Table S1), which have been processed with Frozen Robust Multiarray Analysis (fRMA) with random-effect summarization. ${ }^{20}$ All microarray data sets can be found in the GEO database and Array express (https:// www.ebi.ac.uk/arrayexpress). In principle, the Affymetrix HG-U133+PM platform contains all the perfect match probes of the HG-U133Plus2.0 platform, albeit with some minor reselections. To make the processed data comparable from both microarray types, a chip description file that contains only the shared probes was used, and the processing parameters of this subset were taken from the HG-U133Plus2.0 frmavecs to process data from both platforms. On all Affymetrix microarray data, from experiments performed for this study and data sets from the public GEO database, an extensive quality control was performed. Quality control of the microarray samples has been performed using several quality checks. These checks include the mean value of all Perfect Match probes intensities, negative or extreme ( $>16-$ bit) intensity values, poly-A RNA (sample preparation spike-ins) and labeled cRNA (hybridization spike-ins) controls, $\beta$-actin and glyceraldehyde-3phosphate dehydrogenase $3^{\prime} / 5^{\prime}$ ratio, values and center of intensity of the positive and negative border controls determined by the affyQCReport package, and an RNA degradation value determined by the AffyRNAdeg function from the affy package. Samples from the breast, colon, and prostate data sets that did not pass the quality criteria were removed from further analyses.

\section{Western Blotting}

Western blot analysis was performed using standard $6 \%$ to $15 \%$ SDS-PAGE. Proteins were detected with primary rabbit antibodies (1:2000) for FOXO3 (H144, Santa Cruz Biotechnology, Santa Cruz, CA). Blots were incubated with horseradish peroxidase-conjugated secondary antibodies at $4^{\circ} \mathrm{C}$ for 16 hours. Proteins were visualized with enhanced chemiluminescent (Bio-Rad Laboratories, Hercules, CA) using an ImageQuant LAS 4000 scanner (GE Healthcare, Chicago, IL).

\section{Immunofluorescence and IHC}

For immunofluorescent staining, cells were grown on glass coverslips, fixed using 4\% paraformaldehyde, and blocked with phosphate-buffered saline that contained $2 \%$ bovine serum albumin (Invitrogen, Carlsbad, CA) and $0.1 \%$ normal goat serum (Invitrogen). Cells were incubated with FOXO3 antibody (Foxo3A rabbit monoclonal antibody, 1:500 CST75D8), secondary Alexa563 conjugated antibodies, and 
DAPI (Sigma-Aldrich, St. Louis, MO). Slides were imaged on a Zeiss LSM710 confocal microscope.

For FOXO3 immunohistochemistry (IHC) staining, $4-\mu \mathrm{m}$ sections of formalin-fixed, paraffin-embedded tissue samples were deparaffinized and rehydrated. After blocking of endogenous peroxidase activity, antigen retrieval was performed with TE buffer at pH 9.0 (Dako, Santa Clara, CA) in a water bath at $95^{\circ} \mathrm{C}$ to $96^{\circ} \mathrm{C}$ for 25 minutes. After cooling for at least 15 minutes and washing steps with phosphate-buffered saline, the samples were blocked with $1 \%$ bovine serum albumin in phosphate-buffered saline for 15 minutes. Then the sections were incubated with FOXO3 antibody (1:50, CST-75D8) for 1 hour at room temperature. Visualization was achieved using the Dako Envision+TM System anti-rabbit horseradish peroxidase. As a counterstain, Gill's 2-hematoxylin was used. Images were generated with a three-dimensional Histech scanner. Negative controls consisted of sections that underwent similar staining procedures without addition of the primary antibody. As a positive control, nonmalignant tonsil tissue was used.

\section{Development of the Computational Model for Predicting FOXO Activity}

The signal transduction pathway modeling approach is based on inferring pathway activity from the measured mRNA levels of target genes of the FOXO transcription factor, as readout for PI3K pathway activity, using probabilistic Bayesian network inference. Development of the computational model for FOXO transcriptional activity is based on probabilistic Bayesian network inference as described earlier. ${ }^{11}$ In brief, the parameters that describe the relation between the FOXO transcription complex (TC) and a target gene represent the probability of the respective gene being up-regulated or not, depending on whether the TC is active or not. Furthermore, the parameters that describe the relation between each target gene and its respective Affymetrix probe sets represent the probability of the probe set having a high or low intensity, depending on whether the target gene is up or down (some probe sets may be more discriminating than others). Finally, for each probe set, a threshold was set above which it was called a high intensity and below which it was called low. Parameters that enforce the associations between the FOXO TC and target genes were manually set to improve generalization behavior of the model across different tissue types. ${ }^{11}$ Parameters that describe associations between target genes and their respective probe sets were calibrated on a public data set of human umbilical vein endothelial cells (HUVECs) carrying inducible constitutively active FOXO3.A3-estrogen receptor (ER) (https://www.ncbi.nlm.nih.gov/geo; accession number GSE16573). A threshold for FOXO activity was set using three samples in which constitutively active FOXO.A3 was induced for 12 hours as active FOXO calibration samples, whereas three controls, without induction, were used as inactive FOXO calibration samples. $^{21}$ The model was frozen and applied to Affymetrix microarray data of cell line and tissue samples by entering probe set measurements as observations into the model, inferring backwards FOXO transcription factor activity score as the $\log _{2}$ value of the FOXO transcription factor odds $(\mathrm{p} /(1-\mathrm{p}))$.

Samples are classified as FOXO active if pathway activity exceeds an activity score above 0 , corresponding with an odds active to inactive ratio above 1:1 that the pathway is active, and inactive in case the activity score is $<0$. For validation purposes, FOXO activity analysis was always performed on independent fRMA (unless otherwise indicated) preprocessed Affymetrix HG-U133Plus2.0 microarray data from described experiments and from public GEO data sets.

\section{Identification of Direct Target Genes for FOXO}

For optimal performance, across multiple different tissue types, the mathematical model should contain direct target genes of the FOXO transcription factor. Target genes were manually selected based on extensive scientific evidence for each gene being a direct target gene of the respective TC, including promotor region enhancer motif analysis, transcription factor-binding experiments (electrophoretic mobility shift assay and chromatin immunoprecipitation), gene promoter luciferase reporter experiments, and differential mRNA expression analysis. Available literature retrieved from the MEDLINE database was extensively evaluated using PubMed for FOXO target genes. In addition, literature on FOXO target genes was extracted from Thomson-Reuters' Metacore by selecting only genes that had multiple sources of reliable evidence for being transcriptionally regulated by one or more of the FOXO family members. Ultimately, the target genes were ranked according to literature evidence using a similar method as described earlier. ${ }^{11}$ Only the highest ranked target genes, also included in the list published by van der Vos and Coffer, ${ }^{22}$ were selected as bona fide target genes (Table 1).

\section{SOD2 Level Associated with 0xidative Stress}

To investigate differences in individual FOXO target gene expression levels between FOXO-active samples of healthy and cancer tissue, publicly available microarray data sets were used from healthy and corresponding premalignant or malignant tumor tissue samples (Supplemental Table S1). fRMA-normalized intensities on a $\log _{2}$ scale measured on the different gene-specific probe sets on the microarray reflect gene expression levels. FOXO gene and FOXO target gene expression levels were compared between FOXO-active tumor and healthy tissue samples.

To establish a threshold for $S O D 2$ expression levels in the absence of oxidative stress, means \pm 2 SDs were determined for SOD2 Affymetrix U133 Plus 2.0 probe set values 
Table 1 Selected Forkhead Box-0 Target Genes

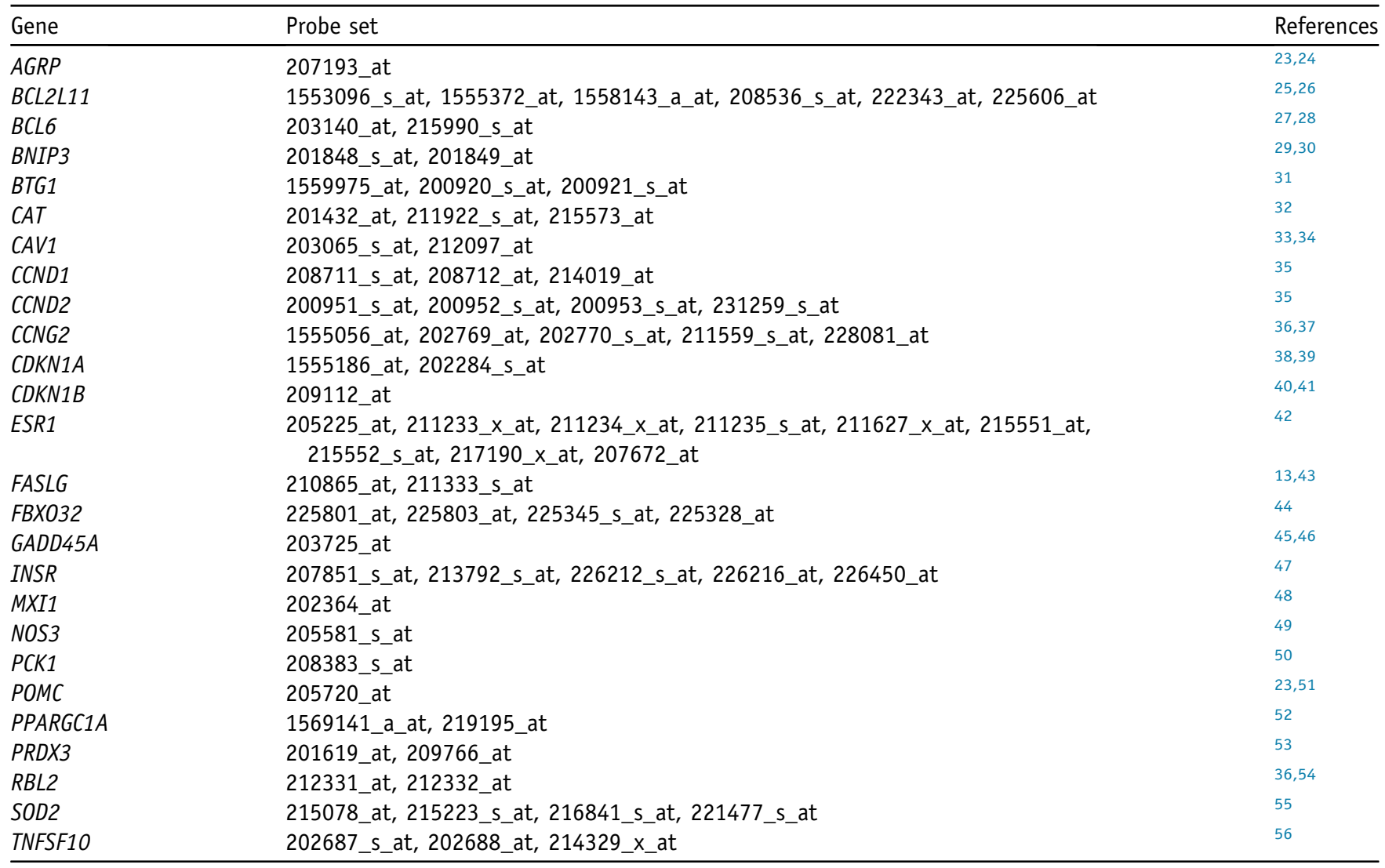

F0X0 target genes selected for model and associated probe sets (Affymetrix HG-U133Plus2.0).

for different types of healthy normal tissue. In FOXO-active samples with SOD2 mRNA levels that exceeded the threshold level of both probe sets, FOXO activity was considered as oxidative stress induced.

\section{Subtyping Breast Cancer Samples from Public Data Sets According to Perou}

Intrinsic breast cancer subtypes of all breast cancer samples were determined from microarray data according to the method described by Parker et $\mathrm{al}^{57}$ and Perou et al. ${ }^{58}$ Intrinsic subtypes were determined from the Affymetrix microarray data using the methods as described by Parker et $\mathrm{al}^{57}$ and the Prosigna Packet Insert (NanoString Technologies, Seattle, WA). fRMA-normalized gene expression of all 50 genes included in PAM50 was extracted from the microarray data using the probe sets associated with the PAM50 genes. The probe set with the highest variance was selected in case more than one probe set was associated with a single gene. Centroids for the luminal A, luminal B, HER2 enriched, basal, and normal-likes were calculated using the samples from GEO database (https://www.ncbi.nlm.nih.gov/ geo; accession number GSE21653) with given subtypes. Next, Pearson correlation coefficients with these centroids were calculated for all samples. Each sample was assigned to the subtype with the highest correlation.

\section{Statistical Analysis}

One-sided Wilcoxon signed-rank statistical tests were performed. $P<0.05$ was considered significant.

\section{Results}

Development of a Computational Model for PI3K-FOXO Activity

A Bayesian network-based computational model for FOXO activity was generated, which infers FOXO transcriptional activity from 26 FOXO target gene mRNA levels in a tissue sample (Figure 1A). Although inferring transcription factor activity from the mRNA level of one target gene is not sufficiently specific, inferring activity from expression levels of a larger number of target genes, typically between 20 and 30, appears to be a highly specific way to quantify associated transcription factor activity. For optimal performance across multiple different tissue types, direct target genes are selected. Because pathway databases such as KEGG (www.genome.jp/kegg) and Biocarta (www. biocarta.com) are inconsistent in this aspect, ${ }^{20}$ genes were manually selected based on scientific evidence from literature (PubMed) and Thomson-Reuters' Metacore. ${ }^{11}$ On the basis of the 26 highest ranked FOXO target genes 


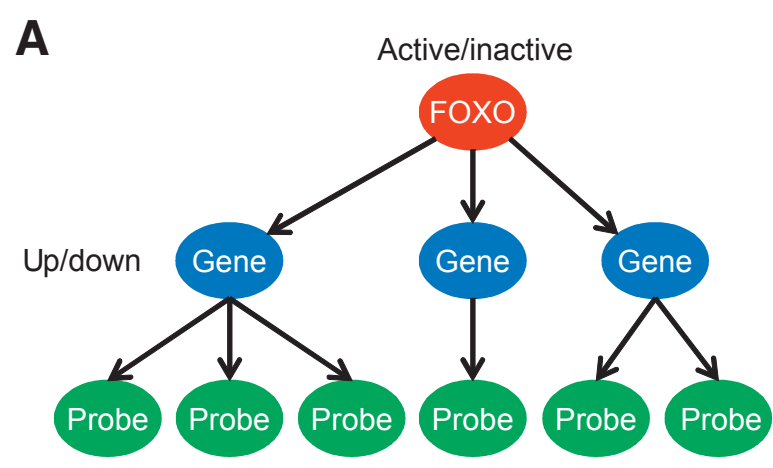

High/low

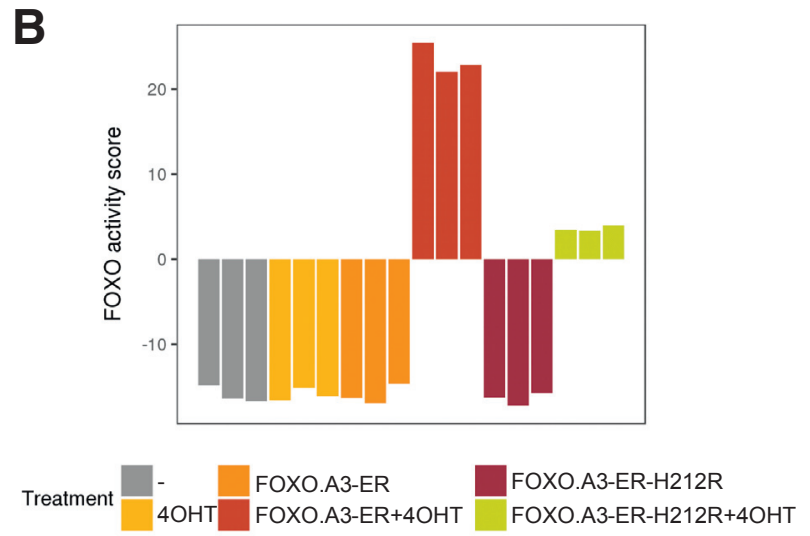

Figure 1 A knowledge-based Bayesian computational model predicting forkhead box-0 (FOXO) activity. A: The Bayesian network structure used as a basis for our modeling approach shown as a simplified model of the transcriptional program of a cellular signal transduction pathway, consisting of three types of nodes: transcription factor, target gene, and microarray probe sets corresponding to target genes. Adapted with permission. ${ }^{11}$ B: Calibration of the computational FOXO model on a public Gene Expression Omnibus data set (https://www.ncbi.nlm.nih.gov/geo; accession number GSE16573), consisting of Affymetrix microarray Plus2.0 expression data from human umbilical vein endothelial cells containing a 4-hydroxytamoxifen (4OHT)-inducible FOX03.A3-estrogen receptor (ER) expression construct, with either wild-type or mutated (H212R) FOXOA3. Each bar represents the inferred FOXO activity score of an individual sample; FOXO is active (values above the horizontal axis) versus inactive (values below the horizontal axis).

and their corresponding probe sets, the Bayesian network-based computational model infering FOXO activity was generated (Figure 1A and Table 1). ${ }^{16,22}$

HUVECs with inducible FOXO activity provided ground truth evidence of FOXO activity status in an untransformed setting and were used to calibrate the model before model freeze. Predictions of the Bayesian model are consistent with known experimental FOXO activity status in the complete HUVEC data set, including independent sample data (Figure 1B). Untreated, 4-hydroxytamoxifen (4OHT)treated, and untreated HUVEC-FOXO3.A3-ER (4OHTinducible $\mathrm{FOXO} 3$ hyperactive mutant) were predicted to have low FOXO activity and therefore active PI3K signaling, as expected in proliferating cells. HUVECFOXO3.A3-ER treated with $4 \mathrm{OHT}$ are predicted to have highly active FOXO, in line with induction of constitutively active FOXO3.A3. In HUVECs that express FOXO3.A3-ER-H212R, a point mutation in the DNA-binding domain, resulting in reduced DNA-binding capacity, the model predicted FOXO to be inactive in untreated and low in 4OHT-treated cells, respectively. ${ }^{21}$ These observations confirm that the model specifically detects transcriptional changes induced by FOXO and is sensitive to low levels of FOXO activity.

\section{Biological Validation of the PI3K-FOXO Model in Breast Cancer Cell Lines}

After calibration, the model was biologically validated in independent breast cancer cell lines, in which ground truth PI3K pathway activity was known. ER-positive, PIK3$\mathrm{CA}^{\mathrm{E} 545 \mathrm{~K}}$ mutant MCF7 and triple-negative MDA-MB-231 cells were stably transduced with a doxycycline inducible FOXO3.A3 expression vector, allowing rapid and controlled induction of $\mathrm{FOXO} 3$ protein expression and transcriptional activity on treatment with doxycycline for 16 hours (Figure 2A). Endogenous FOXO3 protein was predominantly detected in the cytoplasm in untreated and $20 \%$ FBS-stimulated cells, switching to dominant nuclear localization in cells treated with doxycycline, PI3K inhibitor LY294002, and doxycycline in combination with LY294002 (Figure 2B). This shows that nuclear translocation of FOXO3 was induced in a controlled manner in this experimental cell culture system. On Affymetrix mRNA expression data from this cell model, the FOXO model predicted respectively low FOXO activity in untreated (PI3K pathway active) and high FOXO activity in doxycycline-treated (PI3K pathway inactive) MCF-FOXO3.A3 and MDA-MB-231-FOXO3.A3 cells; low FOXO activity in 20\% FBS-treated MCF7 cells (PI3K pathway active) and high activity in doxycycline, LY294002, and combined doxycycline and LY294002-treated cells (all PI3K pathway inactive) (Figure 2, C and D).

To further validate the assay in cells without artificially induced FOXO, two public Affymetrix data sets were available for breast cancer cell line experiments in which the HER2-PI3K pathway activity was actively manipulated, the data being suitable for additional biological validation (Figure 2, E and F). First, the HER2 ligand heregulin- $\beta 1$ is known to activate the PI3K pathway and was found to reduce FOXO activity in MCF7 cells after only 2 hours of exposure (Figure 2E). Second, in the BT-474 breast cancer cell line, siRNA-induced knockdown of HER2 resulted in the expected increase in FOXO activity, associated with reduced PI3K pathway activity (Figure 2F). Finally, a few studies using immune cells have been selected for additional biological validation in noncancer cell types (Figure 2, G and $\mathrm{H}$ ). The cytokine IL-2 is a known inducer of PI3K 
pathway activity in T lymphocytes, causing clonal proliferation. Withdrawal of IL-2 resulted in an increase of FOXO activity in $\mathrm{T}$ cells (Figure 2G), and stimulation with IL-2 induced a decrease in FOXO activity in natural killer cells (Figure $2 \mathrm{H}$ ). Finally, activation of $\mathrm{CD}^{+}$naive $\mathrm{T}$ lymphocytes with anti-CD3/anti-CD28 led to the expected reduction in FOXO activity, indicating increased PI3K pathway activity associated with clonal proliferation (Figure 2I).

Together these results confirm that the computational model predicted PI3K-dependent FOXO activity as expected in independent cancer and noncancer cell samples.

\section{Use of the Pathway Model to Predict and Monitor Response to Drugs}

On the premise that FOXO activity is inversely related to PI3K activity in cell lines, it was investigated whether the FOXO model was capable of predicting response to drugs that target receptor tyrosine kinase activity in independent cancer cell line data sets (https://www.ncbi.nlm.nih. gov/geo; accession numbers GSE51212 and GSE30516).

FOXO activity was scored in an epidermal growth factor receptor (EGFR) mutant HCC827 lung cancer cell line treated with erlotinib (EGFR inhibitor), AZD6244 (selumetinib, MEK inhibitor), or BEZ235 (dactolisib, PI3K/ mTOR dual inhibitor). FOXO scored inactive in untreated samples, indicating the active EGFR/PI3K pathway; on treatment with any of the three drugs, FOXO scored active, confirming that all three drugs were effective in directly and/ or indirectly reducing PI3K pathway activity (Figure 3A). As expected, the effect was maximal with the EGFR inhibitor specifically targeting the mutant EGFR expressed by the HCC827 cell line. In three breast cancer cell lines representing triple-negative (BT20), ER-positive (MCF7), and HER2-positive breast cancer (MDA-MB-453), the FOXO activity score increased as expected when treated with erlotinib, indicating reduced PI3K pathway activity (Figure 3B). In an interesting preclinical study, a known lapatenib-resistant BT474-J4 breast cancer cell line did not respond with an increase in FOXO activity to single-agent lapatinib and foretinib treatment, in contrast to its sensitive counterpart (BT474), whereas the resistant cell line responded with an increase in FOXO activity to the combination therapy, comparable to that seen after treatment of the sensitive cell line with lapatinib alone (Figure 3C).

\section{FOXO Activity in Healthy Colon and Colorectal Cancer Tissue Samples}

For evaluation of the model when used on patient tissue samples, a number of independent selected public data sets from clinical studies were used. First, the FOXO activity model was applied on tissue samples derived from 32 normal colon and 32 adenoma biopsy specimens (https:// www.ncbi.nlm.nih.gov/geo; accession number GSE8671). A clear difference in FOXO activity score was observed between healthy colon and adenoma tissue, showing FOXO to be active [32 (100\%)] and inactive [29 of 32 $(90 \%)]$, respectively, indicating frequent activation of the PI3K pathway in colon adenoma (Figure 4A). Second, the FOXO model was applied on data from normal colon, colon adenoma, and carcinoma tissues (https://www.ncbi.nlm.nih.gov/geo; accession number GSE20916) (Figure 4B). In normal colon tissue, FOXO was predicted active [23 of 24 samples (96\%)]. In most adenoma tissue samples, FOXO was predicted to be inactive [30 of 45 (67\%)], confirming frequent PI3K pathway activity, but less than in the first study (https:// www.ncbi.nlm.nih.gov/geo; accession number GSE8671). In half of the colon carcinoma tissue samples (18 of 36), FOXO was scored inactive, with an inferred percentage of PI3K-active colon cancers lower than in adenoma. In contrast to the benign colon adenoma, colon carcinoma is an invasive cancer, characterized by active PI3K growth factor pathway signaling. This urged us to investigate the possibility of FOXO activity in the presence of PI3K activity. A well-described cause for FOXO activity is cellular oxidative stress, associated with the homeostatic function of FOXO in protection against oxidative damage. ${ }^{12,59}$ This difference in function of FOXO is likely to be reflected in a difference in transcribed target genes. To determine which genes within the used FOXO target gene set would be able to discriminate between FOXO activity in healthy and carcinoma samples, FOXO target gene expression levels were compared between normal colon and colon carcinoma tissue samples, in which FOXO was predicted to be active by the model. SOD2 and $B N I P 3$ gene expression was increased in FOXO-active colon carcinoma samples compared with normal colon tissue (Supplemental Table S1). Both genes play a role in cellular response to oxidative stress and are transcribed by FOXO under these circumstances, making them prime candidates to distinguish between the two modes of FOXO activity. ${ }^{29,55}$

Indeed, comparing SOD2 and BNIP gene expression levels between various FOXO active normal tissues and corresponding premalignant or malignant tumor tissue samples (breast cancer, Barrett esophagus, esophageal cancer, bladder cancer, and gliomas) confirmed increased expression levels of SOD2 and to a lesser extent BNIP3 in FOXO-active samples from aggressive cancer types (Supplemental Table S1). In remarkable contrast, in FOXO active samples of two benign hyperproliferative conditions, colon adenoma and Barrett esophagus, FOXO activity was not associated with increased SOD2 and BNIP3 expression, indicating that in these benign tumors FOXO was activated in a PI3K-regulated manner to control cell division, comparable to healthy tissue. The BNIP3 and SOD2 genes are not unique transcriptional targets of FOXO and can be transcribed by other transcription factors during conditions of oxidative stress. ${ }^{60-62}$ 
A

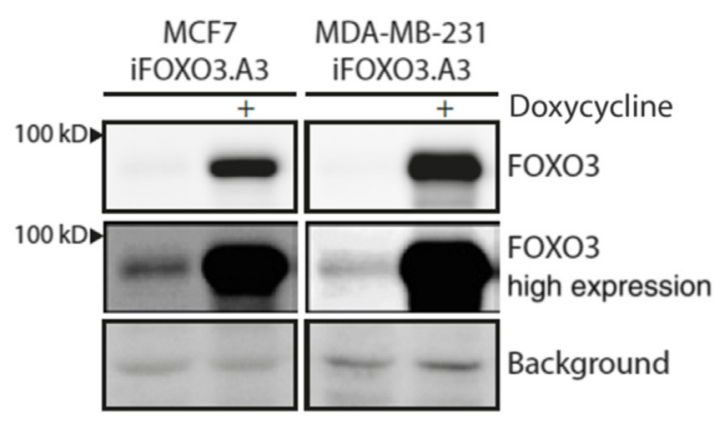

C

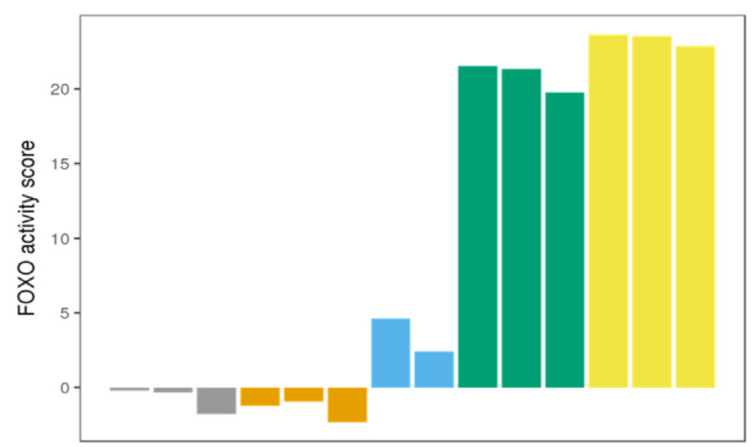

\begin{tabular}{l|l|l|l|l|l} 
Control & 20\% FBS $\square$ LY294002 & Doxycyclin & LY294002 + Doxycyclin
\end{tabular}

\section{B}

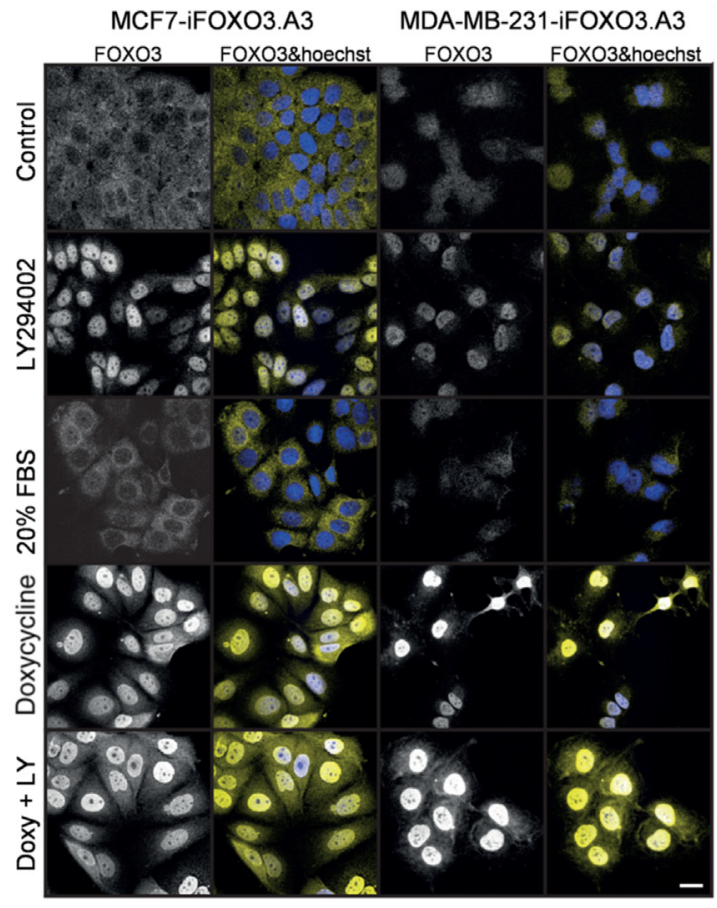

D

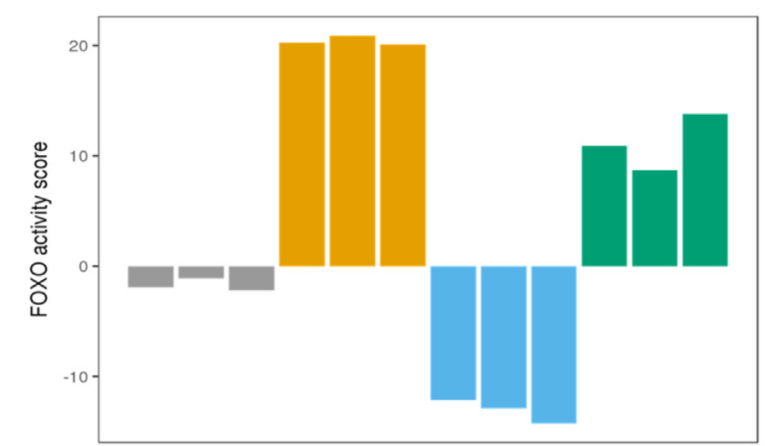

MCF-FOXO3.A3 MCF-FOXO3.A3 + dox MDA-MB-231-FOXO.A3 MDA-MB-231-FOXO.A3 + doX
E

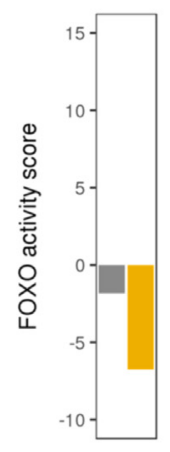

Treatment

MCF7 Control

MCF7 HRG $2 \mathrm{~h}$
$\mathbf{F}$

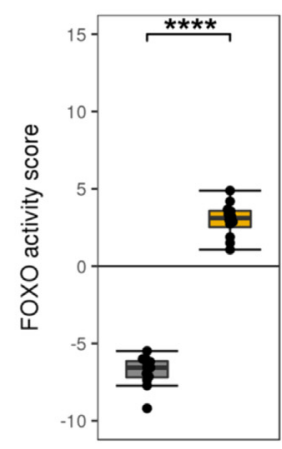

Treatment

由 Control siRNA

由 HER2 SIRNA
G

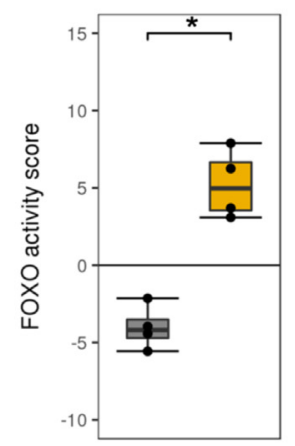

Treatment

由 PBMCs control

\$ PBMCs IL2 withdrawa
H

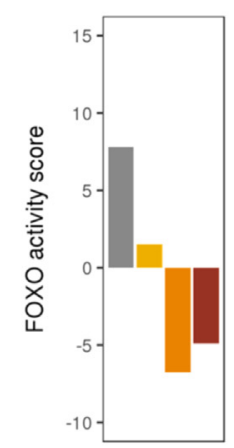

Treatment

NK cells resting

NK cells + IL-2 (2 hrs)

NK cells + IL-2 (8 hrs)

NK cells + IL-2 (24 hrs)
I

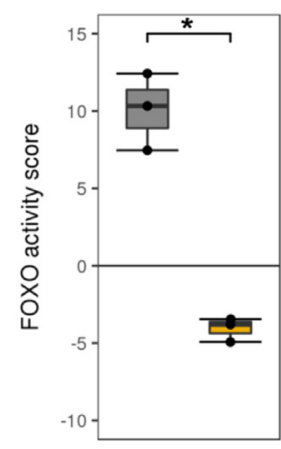

Treatment

麻 Naive

丹 Activated 
For reliable use in distinguishing the two modes of FOXO action, expression levels of these target genes should be positively correlated with FOXO activity during oxidative stress. Correlation between FOXO activity and SOD2/BNIP3 mRNA expression levels was studied in a breast cancer data set from a study in which oxidative stress in individual samples was measured in luminal A, HER2, and triple-negative/basal-like breast cancer tissue using expression levels of the H2AX protein. ${ }^{63}$ In basal-like breast cancer samples, characterized by oxidative stress, FOXO activity was indeed correlated with SOD2 expression $(P<0.0001)$, whereas this correlation was absent in the luminal A breast cancer samples that typically did not have oxidative stress (Supplemental Figure S1). Such a correlation was absent for the $B N I P 3$ target gene. These results provide evidence that under conditions of oxidative stress FOXO is the main transcription factor transcribing the SOD2 gene, whereas regulation of $B N I P 3$ gene expression is likely to be controlled predominantly by other transcriptional regulators [(eg, NF- $\kappa \mathrm{B}$ and the transcription factor encoded by nuclear factor (erythroid-derived 2)-like 2 (NRF2)]. In agreement with this, SOD2 showed the most generalized and profound differential expression between FOXO-active normal tissue samples and corresponding FOXO-active cancer types. On the basis of these results, this gene was selected as the most reliable parameter to distinguish between the two modes of FOXO activity. The SOD2 upper threshold level for PI3K-regulated (nonoxidative stress) FOXO activity was defined as 2 SDs above the mean expression level in normal tissue and was calculated in FOXO-active samples for healthy colon, breast, and prostate tissue separately. Subsequently, the FOXO model in combination with the SOD2 expression threshold was applied to publicly available data sets with data from individual patients with colon, breast, and prostate cancer. In FOXOactive samples from normal tissue, luminal $\mathrm{A}$ and normallike breast cancer, and prostate cancer, SOD2 mRNA levels were in general in the normal range; in contrast, SOD2 was frequently increased in FOXO-active colon cancer, whereas in the more aggressive breast cancer subtypes, SOD2 levels increased in parallel with tumor aggressiveness (Supplemental Figure S2).

\section{F0X03 IHC Staining in Tissue Slides}

Because FOXO was uniformly scored active in the PI3Kregulated growth control mode on normal tissue samples, such a FOXO activity score on a cancer slide that contained normal tissue may potentially obscure PI3K pathway activity in cancer cells. FOXO3 is the most ubiquitously expressed FOXO family member with high relevance for cancer and was consistently expressed in most healthy tissues and in all tumor samples from all cancer types that have been analyzed to date, including breast, colon, prostate, bladder, esophagus, and brain (Supplemental Table S1). FOXO3 IHC staining was developed and tested on colon tissue, to enable identification in a mixed healthy and cancer cell tissue sample the cell type(s) that contributed to an active FOXO score of the whole sample. Although nuclear presence of FOXO protein is a prerequisite for its transcriptional activity, it is not sufficient because functional FOXO activity is dependent on its posttranslational status. ${ }^{64,65}$ However, when a high FOXO activity score is measured using the pathway model, nuclear FOXO IHC staining provides complementary information on the cell type(s) causing the high score. In agreement with our analysis of FOXO activity scores in colon tissue, in healthy colon tissue, FOXO3 was localized in the nucleus in mucosa and other nontumor (interstitial) cells and was cytoplasmic in the few (dividing) crypt cells; however, in colon adenoma cells, FOXO3 was localized in the cytoplasm (inactive), and in colon carcinoma tissue, some areas showed nuclear and other areas of cytoplasmic staining (Figure 4C). Total cellular FOXO protein expression levels (nuclear plus cytoplasmic) were observed to vary among stained tissue slides. These differences are most likely attributable to differences in protein turnover because on mRNA level FOXO expression levels were remarkably similar among different tissue types (Supplemental Table S1).

Prediction of FOXO Activity Mode (PI3K Regulated or Oxidative Stress) in Colon Adenoma and Primary Colon, Breast, and Prostate Cancer Tissue

Analysis of a large set of healthy colon tissue samples $(n=121)$ allowed a threshold setting for normal SOD2 mRNA levels in FOXO-active samples (Figure 5A and Supplemental Figure S2A). Subsequently, an extended independent set of patient colon adenoma and carcinoma sample data were compiled and FOXO activity and SOD2 expression levels determined. In normal colon samples, only $2.6 \%$ of FOXO active samples had SOD2 expression that

\footnotetext{
Figure 2 Correct prediction of forkhead box-0 (FOXO) and phosphatidylinositol 3-kinase (PI3K) activity in breast cancer cell lines and other cell types. A: Western blot analysis of F0X03 expression levels in MCF7-F0X03.A3 and MDA-MB-231 cells cultured in the absence or presence of doxycycline for 16 hours to induce F0X03 expression. The lower F0X03 blot represents a longer exposure of the same blot. B: Immunofluorescent staining of F0X03 (single F0X0 staining black and white; overlay in yellow) and DNA (Hoechst blue) in MCF7-F0X03.A3 and MDA-MB-231-F0X03.A3 cells treated with 20\% fetal bovine serum (FBS), PI3K inhibitor LY294002, doxycycline, or a combination of doxycycline and LY294002 for 16 hours. C-I: Biological validation of the computational FOXO model in various cell types. C: MCF7-F0X03.A3 cells treated with 20\% FBS, PI3K inhibitor LY294002, doxycycline, or a combination of doxycycline and LY294002 for 16 hours. D: MCF7-F0X03.A3 and MDA-MB-231 cells treated with dox for 16 hours. E: GSE8471; breast cancer MCF7 cell line treated with heregulin- $\beta 1$ (HRG). F: GSE71347; siRNA-induced HER2 knockdown in breast cancer cell line (BT-474). G: GSE7345; IL-2 withdrawal from T lymphocytes. H: GSE8059; IL-2 stimulation of natural killer (NK) cells. I: GSE71566; CD4 ${ }^{+}$T lymphocytes from human umbilical cord blood, naive and activated with antiCD3/anti-CD28. GSE accession numbers can be found at Gene Expression 0mnibus database (https://www.ncbi.nlm.nih.gov/geo). ${ }^{*} P<0.05,{ }^{* * * * P}<0.0001$ (one-sided Wilcoxon signed-rank statistical tests were performed). Scale bar $=20 \mu \mathrm{m}$.
} 

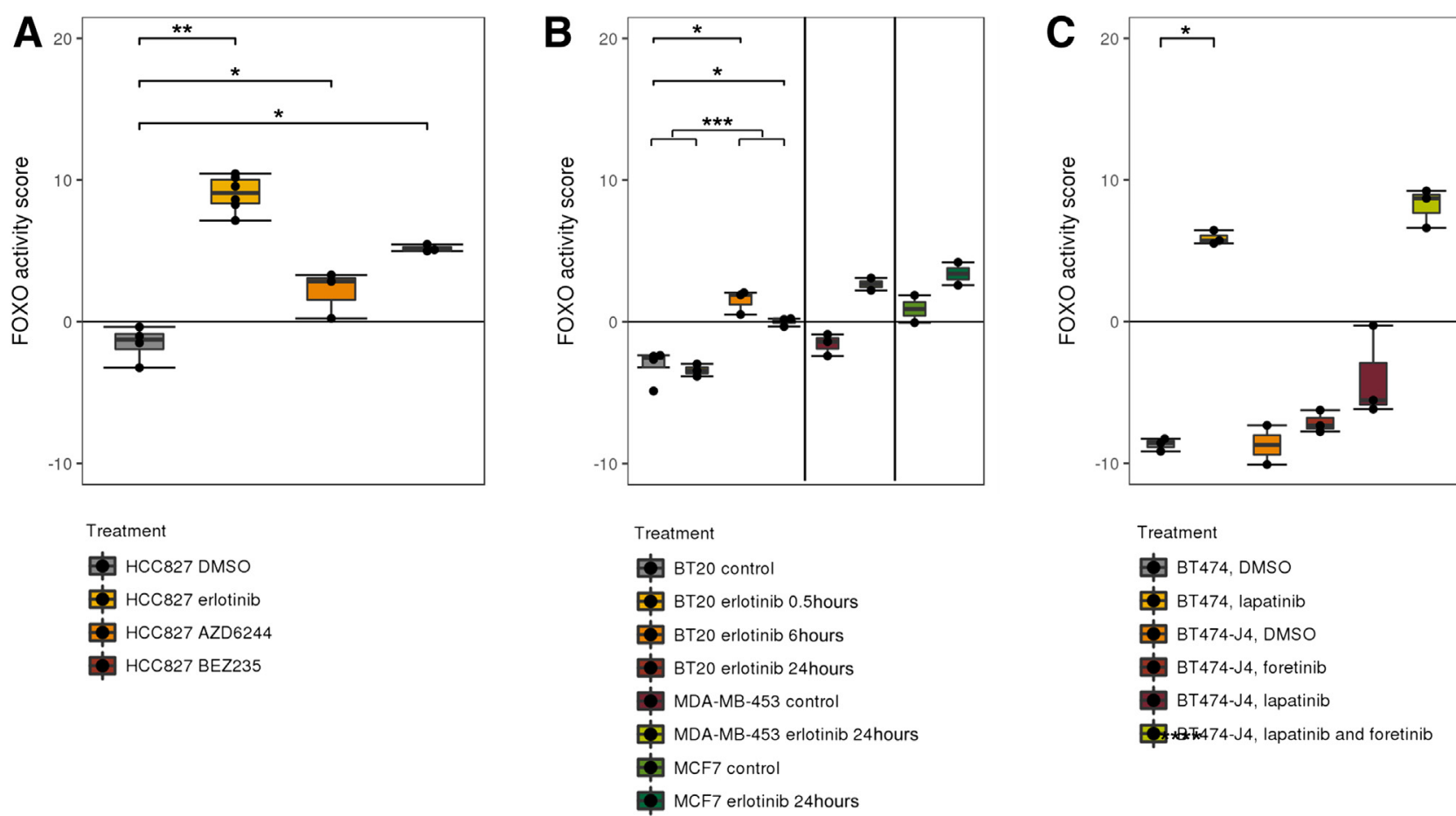

Figure 3 Functional phosphatidylinositol 3-kinase (PI3K) activity prediction correlates with corresponding targeted therapy effects in cancer cell line samples. A: The lung cancer cell line HCC827 (https://www.ncbi.nlm.nih.gov/geo; accession number GSE51212) was treated either vehicle [dimethyl sulfoxide (DMSO)] ( $n=4)$, erlotinib $(n=3)$, AZD6244 (selumetinib) $(n=3)$, or BEZ235 (dactolisib) $(n=3)$, as indicated. Erlotinib inhibits epidermal growth factor receptor; selumetinib inhibits specifically MEK1/MEK2; dactolisib is a dual inhibitor of PI3K and mechanistic target of rapamycin. B: Three breast cancer cell lines (GE0 accession number GSE30516) representing triple-negative (BT20), estrogen receptor-positive (MCF7), and HER2-positive breast cancer (MDA-MB453) were treated with erlotinib (periods indicated in the figure). C: Breast cancer cell lines (BT474, HER2-positive and lapatinib-sensitive; BT474-J4, acquired lapatinib-resistance) (GE0 accession number GSE16179) treated with lapatinib, foretinib (GSK1363089), lapatinib, and foretinib combined or vehicle. F0X0 activity scores plotted in groups using boxplots. ${ }^{*} P<0.05,{ }^{* *} P<0.01$, and ${ }^{* * *} P<0.001$ (one-sided Wilcoxon signed-rank statistical tests were performed).

exceeded the threshold level. In the few adenoma samples that were FOXO active $(n=12,16 \%)$, SOD2 levels were above the threshold in half. In the carcinoma samples, onethird of the samples were scored FOXO active, of which $54 \%$ with above threshold SOD2 expression.

Similarly, a compiled set of data from patients with breast cancer was analyzed (Figure 5B and Supplemental Figure S2B). Before FOXO activity analysis, breast cancer tumor subtyping in all cancer data sets was performed using the PAM50 algorithm to ensure that the subtypes in all data sets were similarly determined. ${ }^{57}$ In line with the findings in healthy colon tissue, FOXO was predicted to be generally active in normal breast tissue $(90 \%)$ and similar in normallike (96\%) and luminal A (89\%). In luminal B, HER2, and basal subtypes, $34 \%, 18 \%$, and $17 \%$, respectively, scored low for FOXO activity, indicating PI3K pathway activity. An increasing percentage of FOXO active samples with elevated SOD2 (above threshold set in healthy breast tissue) was observed with increasing cancer subtype aggressiveness: from $4.7 \%$ in luminal A to $71 \%$ in basal breast cancer.

To provide additional evidence of correct differentiation between FOXO activity in growth control versus oxidative stress mode using FOXO activity in combination with
SOD2 mRNA level, the already mentioned study by Gruosso et $\mathrm{al}^{63}$ was separately analyzed (Supplemental Figure S3B). The results with respect to the frequency of oxidative stress in luminal A, HER2, and basal-like breast cancer were highly comparable to the results described by the authors.

In normal prostate and prostate cancer samples of patients with lower Gleason score tumors (Gleason score 4 to 7), FOXO was active in $91 \%$ and $85 \%$, respectively. Too few samples of patients with high Gleason score tumors (Gleason score 8 to 9 ) were available to draw any comparative conclusions (Supplemental Figure S3A). Interestingly, in none of the FOXO-active primary prostate cancer samples was SOD2 expression increased over the threshold level set for normal tissue, indicating that for lower Gleason score prostate cancer PI3K pathway activity can be safely inferred from the FOXO activity score and was inactive in most prostate cancer samples (Supplemental Figure S2C).

\section{Identifying Tumors with an Active PI3K Pathway}

To facilitate inference of functional PI3K pathway activity, a simplified decision tree was generated based on two 

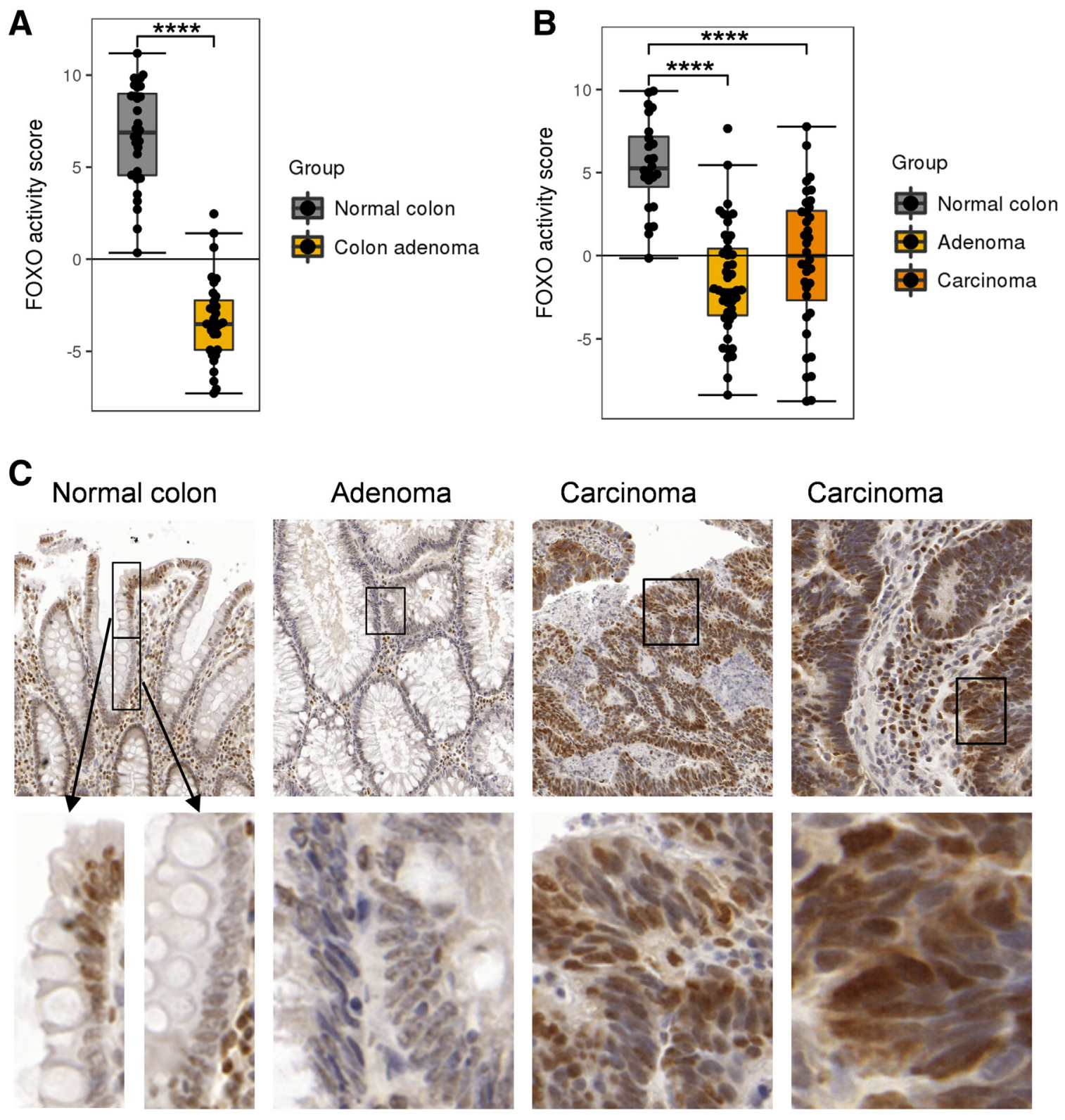

Figure 4 Predicted forkhead box-0 (FOXO) activity corresponds to cellular localization in tissue samples from patients with colon cancer. A: Biological validation of the computational FOX0 model on a public data set (https://www.ncbi.nlm.nih.gov/geo; accession number GSE8671), with corresponding samples in individuals with normal colon and colon adenoma. FOXO activity scores plotted in groups using boxplots. B: Biological validation of the computational FOXO model on a public data set (GEO accession number GSE20916), with samples of healthy colon, colon adenoma, and colon carcinoma tissue. C: Immunohistochemical staining of F0X03 and hematoxylin in normal colon, colon adenoma, and two carcinoma samples (human). Boxed areas are shown at higher magnification in the bottom row. ${ }^{* * *} P<0.0001$ (one-sided Wilcoxon signed-rank statistical tests were performed). Original magnification: $\times 50$ (C, top row, left three images); $\times 100$ (C, top row, rightmost image).

premises: FOXO is expressed in cancer cells in the sample and measured FOXO activity derives from cancer cells (Figure 6 and Supplemental Figure S4). Assuming the PI3K pathway is active in oxidative stress mode, for each investigated cancer type, these samples can be added (Figure 5) to the number of samples with inactive FOXO (indicating active PI3K pathway) to calculate the total number and percentage of patients likely to have a tumor with an active PI3K pathway. The calculated percentage of PI3K pathway active samples was between $8 \%$ and $13 \%$ in normal tissue (colon, breast, prostate) and quite similar in luminal A and normal-like breast cancer and low Gleason score prostate cancer $(13 \%, 15 \%$, and $15 \%$, respectively); in luminal B, HER2, and basal breast cancer, the percentage samples with PI3K pathway activity was much higher $(45 \%, 45 \%$, and $76 \%$, respectively). Interestingly, the percentage of PI3K pathway active samples was already maximal in colon adenoma and did not further increase in carcinoma (92\% and $85 \%$ of samples, respectively). 


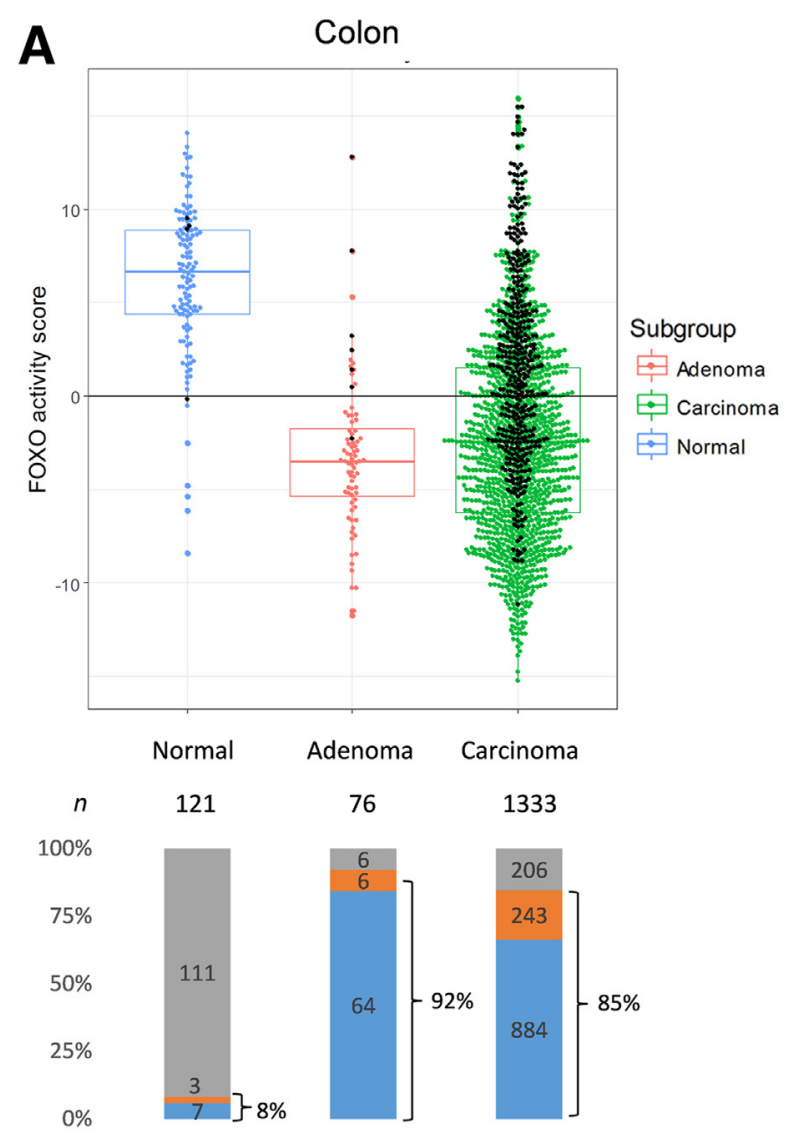

m FOXO inactive $=$ FOXO active-SOD2 high $m$ FOXO active-SOD2 low

B

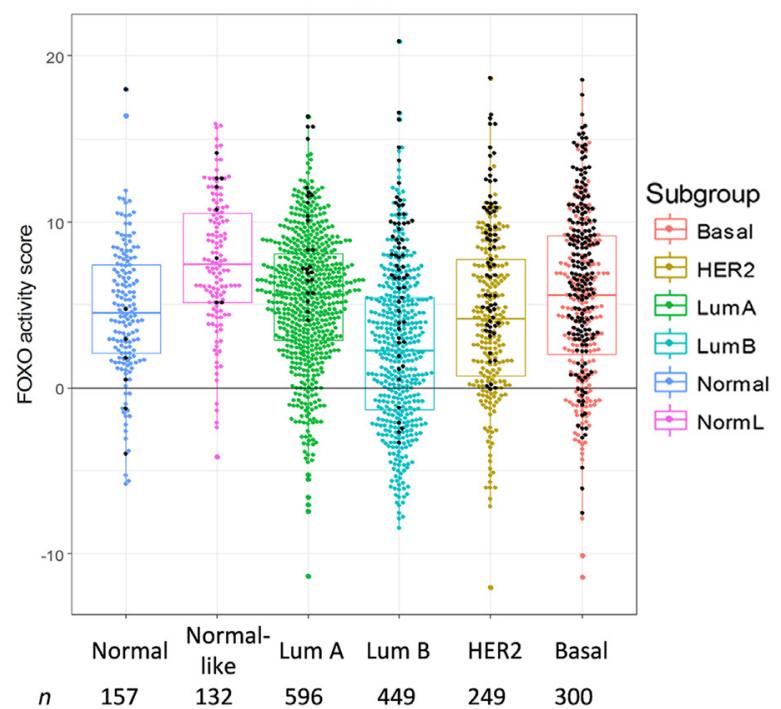

\section{Discussion}

\section{A Knowledge-Based Bayesian Model for Measuring FOXO and PI3K Pathway Activity in a Tissue Sample}

The PI3K pathway is an important oncogenic pathway, and many targeted drugs aim at blocking it at multiple locations. Improving response rates to $\mathrm{PI} 3 \mathrm{~K}$ pathway inhibitors requires tests that reliably assess functional PI3K pathway activity in cancer samples. FOXO transcription factors are negatively regulated by the PI3K pathway and can in principle be used as an inverse readout for PI3K pathway activity. ${ }^{5,12,66}$ To measure PI3K pathway activity in cancer tissue samples, a computational knowledge-based Bayesian network was developed to infer FOXO transcriptional activity from established FOXO target gene mRNA expression levels to be measured in the tissue sample at hand. ${ }^{11}$ The different FOXO members are redundant, and a comparative analysis of FOXO1-, FOXO3-, and FOXO4-induced gene regulation indicates a large overlap among the transcriptional profiles of each FOXO member. ${ }^{16,22,67}$ Therefore, our FOXO activity model, which incorporates knowledge on regulation of direct FOXO target genes, performs as a general FOXO activity predictor.

Calibrating and subsequently freezing this Bayesian model on FOXO-inducible HUVECs resulted in a computational FOXO model that predicted FOXO activity as expected in breast cancer cell lines with constitutively active FOXO3, on incubation with PI3K pathway targeting drugs, or on manipulation of HER2 receptor activity. The observation in FOXO-inducible MCF7 cells that FOXO is scored less active in cells treated with the PI3K inhibitor drug LY294002 compared with ectopic FOXO activation is readily explained by higher FOXO3 protein levels induced by ectopic expression and/or as a result of positive growth factor signaling feedback in the case of treatment with LY294002. Pharmacologic inhibition of the PI3K pathway may initiate a growth factor feedback response that can reestablish growth factor signaling, which constitutes a major component of drug resistance development in cancer cells. $^{6,7,68}$

For extended model validation in other cell types, three data sets from $\mathrm{T}$ lymphocytes (including natural killer and $\mathrm{CD}^{+} \mathrm{T}$ cells) activated with various stimuli were analyzed. The measured decrease in FOXO score associated with

\footnotetext{
Figure 5 SOD2 expression distinguishes phosphatidylinositol 3-kinase (PI3K) and oxidative stress-mediated forkhead box-0 (FOX0) activity in tissue samples from patients with cancer. FOXO-active samples having a SOD2 expression level that is higher than the threshold of SOD2 expression (means \pm 2 SDs in corresponding normal tissue) shown as black dots indicate samples with oxidative stress-induced FOXO activity. Other colors indicate samples in which SOD2 expression is in the normal range, indicating FOXO might not be active in the oxidative stress mode. A: Colon cancer. B: Breast cancer. Data are expressed as the FOXO activity scores plotted in groups using boxplots as well as dots for every unique sample. Lum, luminal.
} 

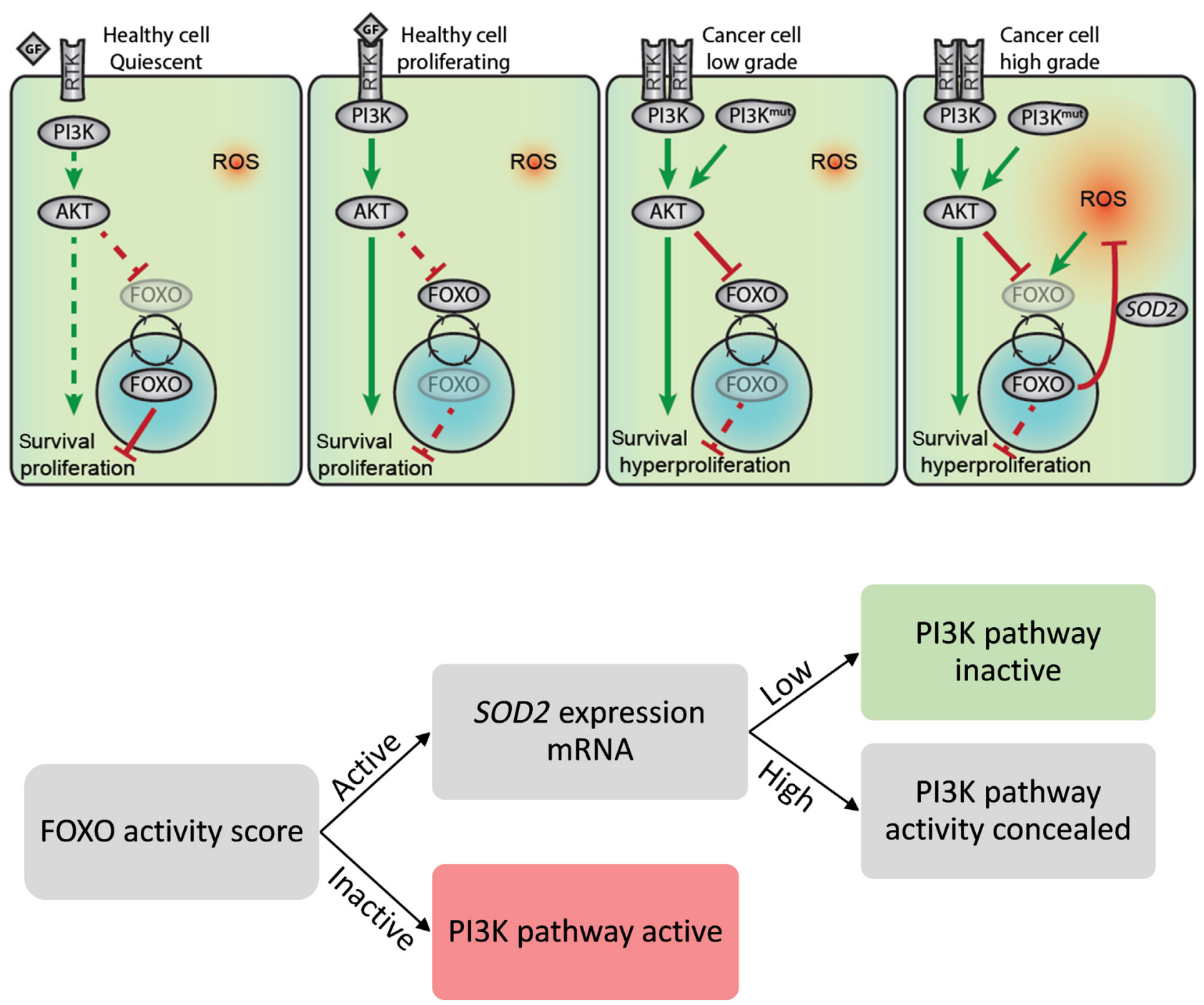

Figure 6 The phosphatidylinositol 3-kinase (PI3K)-forkhead box-0 (-FOX0) pathway and distinction between tumor suppressive and oxidative stress mode of FOXO activity. PI3K-FOXO pathway and relation with SOD2 target gene expression. In healthy normal tissue, FOXO induces transcription of target genes that control cell division. When the PI3K pathway is activated, by stimuli from the microenvironment (proliferating healthy cell) or by genomic mutations (cancer cell), FOXO activity is blocked and FOXO translocates to the cytoplasm, resulting in loss of control over cell division. 0xidative stress associated with rapid proliferation induces alternative activation of FOXO with the function to protect against reactive oxygen species (ROS); the resultant FOXO target gene expression profile is slightly changed to include SOD2. Decision tree to decide on PI3K activity in a tissue sample. This simplified decision tree is based on the assumptions that FOXO is expressed in the cancer cells and there is limited contamination with healthy tissue. A more detailed decision tree can be found in Supplemental Figure S4.

lymphocyte activation reflects well-known induction of PI3K pathway activity necessary for appropriate clonal T-cell expansion. ${ }^{69}$ This provides evidence that the model can also be applied to nonmalignant cells, which was expected because the FOXO target genes were not selected for their role in cancer, but for measurement of FOXO activity irrespective of cell type.

After validation, potential use of the model for drug development purposes was illustrated using data from a number of cancer cell lines. In three breast cancer cell lines and in lung cancer cells with mutated hyperactive EGFR, the model measured an increase in FOXO activity on treatment with the EGFR inhibitor erlotinib, reflecting effective inhibition of PI3K pathway activity. In addition, treatment of the lung cancer cell line with a dual mechanistic target of rapamycin-PI3K inhibitor (BEZ235, dactolisib) and a MEK1/2 inhibitor (AZD6244, selumetinib) similarly resulted in increased FOXO activity but less than caused by erlotinib. This result illustrates the quantitative nature of the pathway activity score and was as expected because signal transduction initiated by EGFR leads to inactivation of FOXO via the PI3K-AKT and RAS-MEK-ERK-MDM2 pathways. ${ }^{70}$ Finally, the restoration of FOXO activity (and inhibition of PI3K pathway activity) that was observed in a lapatinib-resistant breast cancer cell line when adding the multikinase inhibitor foretinib to lapatinib was in full agreement with the effects on cell growth as described by Liu et al. ${ }^{71}$ 
Thus, the Bayesian model correctly predicted FOXO and PI3K activity in multiple cell cultures, providing biological validation of the model. However, the difference in response of the lung cancer cell line to the three drugs that target different elements of the signaling pathways downstream of EGFR illustrates that to make an optimal choice with respect to a targeted drug, additional analysis (eg, genomic mutation analysis) may be required to establish the underlying cause of PI3K pathway activity.

The reasons the Bayesian approach works well to analyze different cell types has been discussed before. ${ }^{10,11}$ Many earlier approaches to pathway modeling have derived or composed signaling pathway mRNA signatures from genes of which the encoded proteins are known to play a role in a certain signaling pathway. ${ }^{72}$ The major disadvantage of such approaches is that measuring mRNA levels as a surrogate for measuring active signaling proteins is unreliable for predicting pathway activity; however, the approach can be suited for biomarker or drug target discovery purposes. A growth factor pathway modeling approach that merits discussion is the Boolean logic-based model of Kirouac et al, ${ }^{73}$ which models activity of the growth factor signaling network upstream of the FOXO transcription factor to predict targeted drug resistance, using protein measurements as input. This model may have difficulty in predicting functional activity of FOXO because of missing processes upstream in the growth factor pathway regulating FOXO activity, whereas in the Bayesian model this issue is bypassed by looking only at the result of FOXO transcriptional activity. In addition, application of the model is likely to be tissue type specific because its parameters have been estimated from experimental data, which is not the case in the Bayesian model that can be used across cancer types. On the other hand, as mentioned before, such models are likely to provide complementary biomarker information, especially in experimental settings.

\section{Distinguishing Different Mechanisms That Regulate FOXO Activity}

In cancer tissue, interpretation of FOXO activity is more complex. Unexpectedly, in colon carcinoma as well as luminal B, HER2, and basal breast cancer subtypes, where PI3K pathway activity is common, a large portion of the samples were predicted to have an active FOXO transcription factor. ${ }^{2,74}$ This finding suggested that simple inversion of FOXO activity status to infer PI3K pathway activity was not valid in all cancer tissue samples and moreover that FOXOs are not passive bystanders in high-grade cancers. A differentiator was necessary to distinguish between PI3K regulated and putative non-PI3K-regulated FOXO activity. FOXOs function as regulators of cellular homeostasis and respond to various adverse cellular conditions, including DNA damage, high levels of reactive oxygen species, and low nutrient availability. ${ }^{12,75,76}$ Therefore, an active PI3K pathway may be present in combination with active FOXOs.
We hypothesized that the different functional roles of FOXO should be reflected in changes in FOXO target mRNA expression profiles. Comparing FOXO target gene expression levels between multiple FOXO-active cancer samples and corresponding (FOXO-active) healthy tissue samples revealed SOD2 and BNIP3 as distinguishing FOXO target genes in all investigated cancer types, typified by increased expression in the FOXO-active cancer samples. Both SOD2 and BNIP3 are induced in the presence of cellular oxidative stress. ${ }^{29,55,77}$ However, during cellular oxidative stress, NRF2 and NF- $\kappa \mathrm{B}$ transcription factors may also become activated to transcribe an overlapping subset of oxidative stress target genes, including SOD2 and BNIP3. Although not excluding a contribution of the NF- $\kappa B$ transcription factor to SOD2 target gene levels, these results firmly support FOXO-induced SOD2 transcription during oxidative stress, in contrast to the BNIP3 gene, which is likely to be preferentially transcribed by other transcription factor(s) under these circumstances.

Because cellular oxidative stress is a common phenomenon in tumors and an alternative inducer of FOXO activation, these findings point toward FOXO activation in tumors suffering from oxidative stress regardless of the PI3K status (Figure 6). ${ }^{12,78-80}$ Adding information on SOD2 expression level to the FOXO activity score classified FOXO-active luminal A and normal-like breast cancer and lower Gleason score prostate cancer samples in general as having PI3K-regulated FOXO activity, with the PI3K pathway consequently inferred as inactive and FOXO active to control cell division. Indeed, these cancer types are typically more differentiated and slow growing and driven by the ER and androgen receptor pathways, respectively, in the absence of an active PI3K pathway. In contrast, in aggressive breast cancer subtypes, luminal B, HER2, and basal, tissue samples were scored inactive for FOXO (indicating an active PI3K pathway) or FOXO activity was increasingly classified as oxidative stress induced. As shown, these results are in full agreement with the results from a study in which oxidative stress was measured in luminal, HER2, and triple-negative breast cancer samples. ${ }^{63}$ Summarizing, in good prognosis breast and prostate cancer samples, FOXO transcriptional activity was generally active in the PI3K-regulated growth control mode, whereas in more aggressive cancers, FOXO was inactivated by PI3K or activated in oxidative stress mode. Interestingly, this also reveals that oxidative stress-associated FOXO activity may actually function to support tumor growth by protecting the cell from oxidative damage and simultaneously stimulate the growth factor PI3K-AKT pathway. ${ }^{81}$ Indeed, in the study from Gruosso et al, ${ }^{63}$ the level of oxidative stress in breast cancer samples correlated positively with mitotic index. This study thus nicely complements our results by adding evidence of a higher proliferation rate in tumors with oxidative stress, which is likely to be attributable to increased PI3K pathway activity. In this respect, our observations are fully in line with the recent discovery that 
FOXO can suppress and support cancer growth and metastasis and also explain why various clinical studies aimed at correlating FOXO activity to clinical outcome have resulted in contradicting conclusions. ${ }^{64,65,81}$ The mitotic index is predictive of response to chemotherapy, suggesting that the FOXO-SOD2 model may have value for predicting response to chemotherapy in addition to predicting response to $\mathrm{PI} 3 \mathrm{~K}$ pathway inhibition. ${ }^{82}$ This observation puts targeting FOXO forward as a potential treatment strategy for selected high-grade cancers. Also of interest, a pathogenetic role of FOXO transcription factors is not limited to cancer, and FOXO1 and 3A inhibitors are being developed by several pharmaceutical companies with an initial focus on treatment of diabetes. ${ }^{83-85}$ This development may conceivably pave the way for the use of FOXO inhibition in cancer.

\section{Use of the Computational FOXO Model to Identify PI3K Pathway Activity in an Individual Cancer Tissue Sample}

The intended future use of our computational model is to assess functional PI3K pathway activity in individual cancer tissue samples, to facilitate choice of a targeted drug or other therapy, or to assess therapy response. Using our optimized FOXO computational model to assess FOXO activity, the probability of PI3K pathway activity can be derived using a (simplified) decision tree or the more complex decision tree if significant contamination with normal cells is expected (Figure 6 and Supplemental Figure S4). In the analyzed clinical studies, counting all samples that were scored as FOXO inactive or activated by oxidative stress provided an indication of the total number of patients who might have benefited from PI3K pathway inhibitor treatment. In the low-grade luminal $\mathrm{A} /$ normal-like and lower Gleason score prostate cancer groups, the calculated percentage of PI3Kactive tumors was close to the percentage of PI3K-active healthy tissue samples (approximately $10 \%$ to $15 \%$ ), whereas in higher-grade breast cancer, this increased to three-quarters in the basal breast cancer group. These results are in perfect agreement with the PI3K pathway being the most frequently activated pathway in cancer, especially in the more aggressive tumors. It cannot be excluded that these results still underestimate the real number of PI3K-active samples because of incidental contamination of the cancer sample with healthy tissue, causing a false-positive (PI3Kregulated) FOXO activity score. Complementary FOXO3 staining may be considered when a cancer sample that contains a significant amount of normal tissue is scored FOXO active to confirm that nuclear FOXO is indeed present in the cancer cells. The developed IHC staining performed well in identifying nuclear, potentially active, FOXO in cells in a tissue slide. The observed differences in total FOXO protein expression between cells are probably attributable to active degradation of cytoplasmic localized FOXOs. ${ }^{64,65}$ This phenomenon does not interfere with the intended use of the staining, which is to identify the presence of nuclear staining to help interpret an active FOXO activity score obtained on a tissue sample.

Taking this into account, we expect our FOXO model to provide a robust method for quantitative determination of functional PI3K pathway activity in tissue samples and to improve decision making on the use of drugs that target the receptor tyrosine kinase-PI3K-AKT pathway or chemotherapy, aiming at increased treatment efficacy rates. Complementary genomic analysis to identify a mutational cause for abnormal PI3K pathway activity will be helpful to decide which PI3K pathway targeted drug is likely to be most effective, depending on its point of action in the pathway. The model is expected to be applicable to many different tumor types. To enable use on formalin-fixed, tissue-embedded tissue slides, the model has been adapted for real-time quantitative PCR mRNA measurements as input. Monitoring of therapy response and resistance, for example in a neoadjuvant or window-of-opportunity setting, is another envisioned as well as quantitative assessment of drug response during drug development.

\section{Acknowledgments}

We thank Laurent Holtzer for developing and contributing the quality control assessment for the Affymetrix data.

H.v.O. analyzed data, studied biology of FOXO pathway, developed the model and graphics, and wrote the manuscript; M.H. did cell modeling, performed cell culture fluorescent staining, provided expertise in FOXO experiments, and contributed to discussions and writing; C.D.-d.V. developed and performed IHC FOXO staining; R.V. researched data for discovery of oxidative stress-associated FOXO target genes; M.D. performed SOD2 analysis and generated graphics; W.V. performed computational Bayesian modeling and wrote the manuscript; B.B. provided expertise in FOXO biology experiments and contributed toward discussions and writing; A.v.d.S. conceived clinical scientific concept, researched data, provided insights on biology of pathway model development and clinical relevance/context, and wrote the manuscript.

\section{Supplemental Data}

Supplemental material for this article can be found at https://doi.org/10.1016/j.ajpath.2018.05.020.

\section{References}

1. Ashley EA: Towards precision medicine. Nat Rev Genet 2016, 17 : 507-522

2. Vogelstein B, Papadopoulos N, Velculescu VE, Zhou S, Diaz LA Jr, Kinzler KW: Cancer genome landscapes. Science 2013, 339: 1546-1558

3. van de Stolpe A: On the origin and destination of cancer stem cells: a conceptual evaluation. Am J Cancer Res 2013, 3:107-116 
4. Hanahan D, Weinberg RA: Hallmarks of cancer: the next generation. Cell 2011, 144:646-674

5. Fruman DA, Rommel C: PI3K and cancer: lessons, challenges and opportunities. Nat Rev Drug Discov 2014, 13:140-156

6. Engelman JA: Targeting PI3K signalling in cancer: opportunities, challenges and limitations. Nat Rev Cancer 2009, 9:550-562

7. Arnedos M, Vicier C, Loi S, Lefebvre C, Michiels S, Bonnefoi H, Andre F: Precision medicine for metastatic breast cancer-limitations and solutions. Nat Rev Clin Oncol 2015, 12:693-704

8. Rodon J, Dienstmann R, Serra V, Tabernero J: Development of PI3K inhibitors: lessons learned from early clinical trials. Nat Rev Clin Oncol 2013, 10:143-153

9. Kwiatkowski DJ, Wagle N: mTOR inhibitors in cancer: what can we learn from exceptional responses? EBioMedicine 2015, 2:2-4

10. Verhaegh W, Van de Stolpe A: Knowledge-based computational models. Oncotarget 2014, 5:5196-5197

11. Verhaegh W, van Ooijen H, Inda MA, Hatzis P, Versteeg R, Smid M, Martens J, Foekens J, van de Wiel P, Clevers H, van de Stolpe A: Selection of personalized patient therapy through the use of knowledge-based computational models that identify tumor-driving signal transduction pathways. Cancer Res 2014, 74:2936-2945

12. Eijkelenboom A, Burgering BM: FOXOs: signalling integrators for homeostasis maintenance. Nat Rev Mol Cell Biol 2013, 14:83-97

13. Brunet A, Bonni A, Zigmond MJ, Lin MZ, Juo P, Hu LS, Anderson MJ, Arden KC, Blenis J, Greenberg ME: Akt promotes cell survival by phosphorylating and inhibiting a forkhead transcription factor. Cell 1999, 96:857-868

14. Kops GJ, de Ruiter ND, De Vries-Smits AM, Powell DR, Bos JL, Burgering BM: Direct control of the forkhead transcription factor AFX by protein kinase B. Nature 1999, 398:630-634

15. Eijkelenboom A, Mokry M, de Wit E, Smits LM, Polderman PE, van Triest MH, van Boxtel R, Schulze A, de Laat W, Cuppen E, Burgering BM: Genome-wide analysis of FOXO3 mediated transcription regulation through RNA polymerase II profiling. Mol Syst Biol 2013, 9:638

16. Webb AE, Kundaje A, Brunet A: Characterization of the direct targets of FOXO transcription factors throughout evolution. Aging Cell 2016, 15:673-685

17. Dull T, Zufferey R, Kelly M, Mandel RJ, Nguyen M, Trono D, Naldini L: A third-generation lentivirus vector with a conditional packaging system. J Virol 1998, 72:8463-8471

18. Meerbrey KL, Hu G, Kessler JD, Roarty K, Li MZ, Fang JE, Herschkowitz JI, Burrows AE, Ciccia A, Sun T, Schmitt EM, Bernardi RJ, Fu X, Bland CS, Cooper TA, Schiff R, Rosen JM, Westbrook TF, Elledge SJ: The pINDUCER lentiviral toolkit for inducible RNA interference in vitro and in vivo. Proc Natl Acad Sci U S A 2011, 108:3665-3670

19. Hornsveld M, Tenhagen $M$, van de Ven RA, Smits AM, van Triest MH, van Amersfoort M, Kloet DE, Dansen TB, Burgering BM, Derksen PW: Restraining FOXO3-dependent transcriptional BMF activation underpins tumour growth and metastasis of E-cadherinnegative breast cancer. Cell Death Differ 2016, 23:1483-1492

20. Shmelkov E, Tang Z, Aifantis I, Statnikov A: Assessing quality and completeness of human transcriptional regulatory pathways on a genome-wide scale. Biol Direct 2011, 6:15

21. Czymai T, Viemann D, Sticht C, Molema G, Goebeler M, Schmidt M: FOXO3 modulates endothelial gene expression and function by classical and alternative mechanisms. J Biol Chem 2010, 285:10163-10178

22. van der Vos KE, Coffer PJ: The extending network of FOXO transcriptional target genes. Antioxid Redox Signal 2011, 14:579-592

23. Kim MS, Pak YK, Jang PG, Namkoong C, Choi YS, Won JC, Kim KS, Kim SW, Kim HS, Park JY, Kim YB, Lee KU: Role of hypothalamic Foxol in the regulation of food intake and energy homeostasis. Nat Neurosci 2006, 9:901-906

24. Kitamura T, Feng Y, Kitamura YI, Chua SC Jr, Xu AW, Barsh GS, Rossetti L, Accili D: Forkhead protein FoxO1 mediates Agrp- dependent effects of leptin on food intake. Nat Med 2006, 12 534-540

25. Dijkers PF, Medema RH, Lammers JW, Koenderman L, Coffer PJ: Expression of the pro-apoptotic Bcl-2 family member Bim is regulated by the forkhead transcription factor FKHR-L1. Curr Biol 2000, 10:1201-1204

26. Gilley J, Coffer PJ, Ham J: FOXO transcription factors directly activate bim gene expression and promote apoptosis in sympathetic neurons. J Cell Biol 2003, 162:613-622

27. Fernandez de Mattos S, Essafi A, Soeiro I, Pietersen AM, Birkenkamp KU, Edwards CS, Martino A, Nelson BH, Francis JM, Jones MC, Brosens JJ, Coffer PJ, Lam EW: FoxO3a and BCR-ABL regulate cyclin D2 transcription through a STAT5/BCL6-dependent mechanism. Mol Cell Biol 2004, 24:10058-10071

28. Tang TT, Dowbenko D, Jackson A, Toney L, Lewin DA, Dent AL, Lasky LA: The forkhead transcription factor AFX activates apoptosis by induction of the BCL- 6 transcriptional repressor. J Biol Chem 2002, 277:14255-14265

29. Mammucari C, Milan G, Romanello V, Masiero E, Rudolf R, Del Piccolo P, Burden SJ, Di Lisi R, Sandri C, Zhao J, Goldberg AL, Schiaffino S, Sandri M: FoxO3 controls autophagy in skeletal muscle in vivo. Cell Metab 2007, 6:458-471

30. Zhao J, Brault JJ, Schild A, Cao P, Sandri M, Schiaffino S, Lecker SH, Goldberg AL: FoxO3 coordinately activates protein degradation by the autophagic/lysosomal and proteasomal pathways in atrophying muscle cells. Cell Metab 2007, 6:472-483

31. Bakker WJ, Blazquez-Domingo M, Kolbus A, Besooyen J, Steinlein P, Beug H, Coffer PJ, Löwenberg B, von Lindern M, van Dijk TB: FoxO3a regulates erythroid differentiation and induces BTG1, an activator of protein arginine methyl transferase 1. J Cell Biol 2004, 164:175-184

32. Nemoto $\mathrm{S}$, Finkel T: Redox regulation of forkhead proteins through a p66shc-dependent signaling pathway. Science 2002, 295:2450-2452

33. Roy UK, Henkhaus RS, Ignatenko NA, Mora J, Fultz KE, Gerner EW: Wild-type APC regulates caveolin-1 expression in human colon adenocarcinoma cell lines via FOXO1a and C-myc. Mol Carcinog 2008, 47:947-955

34. van den Heuvel APJ, Schulze A, Burgering BMT: Direct control of caveolin-1 expression by FOXO transcription factors. Biochem J 2005, 385:795-802

35. Schmidt M, Fernandez de Mattos S, van der Horst A, Klompmaker R, Kops GJ, Lam EW, Burgering BM, Medema RH: Cell cycle inhibition by FoxO forkhead transcription factors involves downregulation of cyclin D. Mol Cell Biol 2002, 22:7842-7852

36. Chen J, Yusuf I, Andersen HM, Fruman DA: FOXO transcription factors cooperate with delta EF1 to activate growth suppressive genes in B lymphocytes. J Immunol 2006, 176:2711-2721

37. Martinez-Gac L, Marques M, Garcia Z, Campanero MR, Carrera AC: Control of cyclin G2 mRNA expression by forkhead transcription factors: novel mechanism for cell cycle control by phosphoinositide 3-kinase and forkhead. Mol Cell Biol 2004, 24: 2181-2189

38. Nakae J, Kitamura T, Kitamura Y, Biggs WH 3rd, Arden KC, Accili D: The forkhead transcription factor Foxo1 regulates adipocyte differentiation. Dev Cell 2003, 4:119-129

39. Seoane J, Le HV, Shen L, Anderson SA, Massague J: Integration of Smad and forkhead pathways in the control of neuroepithelial and glioblastoma cell proliferation. Cell 2004, 117:211-223

40. Medema RH, Kops GJ, Bos JL, Burgering BM: AFX-like forkhead transcription factors mediate cell-cycle regulation by Ras and PKB through p27kip1. Nature 2000, 404:782-787

41. Stahl M, Dijkers PF, Kops GJ, Lens SM, Coffer PJ, Burgering BM, Medema RH: The forkhead transcription factor FoxO regulates transcription of p27Kip1 and Bim in response to IL-2. J Immunol 2002, 168:5024-5031

42. Guo S, Sonenshein GE: Forkhead box transcription factor FOXO3a regulates estrogen receptor alpha expression and is repressed by the 
Her-2/neu/phosphatidylinositol 3-kinase/Akt signaling pathway. Mol Cell Biol 2004, 24:8681-8690

43. Ciechomska I, Pyrzynska B, Kazmierczak P, Kaminska B: Inhibition of Akt kinase signalling and activation of forkhead are indispensable for upregulation of FasL expression in apoptosis of glioma cells. Oncogene 2003, 22:7617-7627

44. Sandri M, Sandri C, Gilbert A, Skurk C, Calabria E, Picard A, Walsh K, Schiaffino S, Lecker SH, Goldberg AL: Foxo transcription factors induce the atrophy-related ubiquitin ligase atrogin-1 and cause skeletal muscle atrophy. Cell 2004, 117:399-412

45. Furukawa-Hibi Y: FOXO forkhead transcription factors induce G2-M checkpoint in response to oxidative stress. J Biol Chem 2002, 277: 26729-26732

46. Tran H, Brunet A, Grenier JM, Datta SR, Fornace AJ Jr, DiStefano PS, Chiang LW, Greenberg ME: DNA repair pathway stimulated by the forkhead transcription factor FOXO3a through the Gadd45 protein. Science 2002, 296:530-534

47. Puig O, Tjian R: Transcriptional feedback control of insulin receptor by dFOXO/FOXO1. Genes Dev 2005, 19:2435-2446

48. Delpuech O, Griffiths B, East P, Essafi A, Lam EW, Burgering B, Downward J, Schulze A: Induction of Mxi1-SR alpha by FOXO3a contributes to repression of Myc-dependent gene expression. Mol Cell Biol 2007, 27:4917-4930

49. Potente M, Urbich C, Sasaki K, Hofmann WK, Heeschen C, Aicher A, Kollipara R, DePinho RA, Zeiher AM, Dimmeler S: Involvement of Foxo transcription factors in angiogenesis and postnatal neovascularization. J Clin Invest 2005, 115:2382-2392

50. Sekine K, Chen YR, Kojima N, Ogata K, Fukamizu A, Miyajima A: Foxo1 links insulin signaling to C/EBPalpha and regulates gluconeogenesis during liver development. EMBO J 2007, 26:3607-3615

51. Harada M, Magara-Koyanagi K, Watarai H, Nagata Y, Ishii Y, Kojo S, Horiguchi S, Okamoto Y, Nakayama T, Suzuki N, Yeh WC, Akira S, Kitamura H, Ohara O, Seino K, Taniguchi M: IL-21-induced Bepsilon cell apoptosis mediated by natural killer T cells suppresses IgE responses. J Exp Med 2006, 203:2929-2937

52. Daitoku H, Yamagata K, Matsuzaki H, Hatta M, Fukamizu A: Regulation of PGC-1 promoter activity by protein kinase B and the forkhead transcription factor FKHR. Diabetes 2003, 52:642-649

53. Chiribau CB, Cheng L, Cucoranu IC, Yu Y-S, Clempus RE, Sorescu D: FOXO3A regulates peroxiredoxin III expression in human cardiac fibroblasts. J Biol Chem 2008, 283:8211-8217

54. Kops GJPL, Medema RH, Glassford J, Essers MAG, Dijkers PF, Coffer PJ, Lam EW, Burgering BM: Control of cell cycle exit and entry by protein kinase B-regulated forkhead transcription factors. Mol Cell Biol 2002, 22:2025-2036

55. Kops GJPL, Dansen TB, Polderman PE, Saarloos I, Wirtz KWA, Coffer PJ, Huang TT, Bos JL, Medema RH, Burgering BM: Forkhead transcription factor $\mathrm{FOXO}$ a protects quiescent cells from oxidative stress. Nature 2002, 419:316-321

56. Modur V, Nagarajan R, Evers BM, Milbrandt J: FOXO proteins regulate tumor necrosis factor-related apoptosis inducing ligand expression. Implications for PTEN mutation in prostate cancer. J Biol Chem 2002, 277:47928-47937

57. Parker JS, Mullins M, Cheang MC, Leung S, Voduc D, Vickery T, Davies S, Fauron C, He X, Hu Z, Quackenbush JF, Stijleman IJ, Palazzo J, Marron JS, Nobel AB, Mardis E, Nielsen TO, Ellis MJ, Perou CM, Bernard PS: Supervised risk predictor of breast cancer based on intrinsic subtypes. J Clin Oncol 2009, 27:1160-1167

58. Perou CM, Sorlie T, Eisen MB, van de Rijn M, Jeffrey SS, Rees CA, Pollack JR, Ross DT, Johnsen H, Akslen LA, Fluge O, Pergamenschikov A, Williams C, Zhu SX, Lønning PE, BørrensenDale AL, Brown PO, Botstein D: Molecular portraits of human breast tumours. Nature 2000, 406:747-752

59. van den Berg MCW, Burgering BMT: Integrating opposing signals toward forkhead box O. Antioxid Redox Signal 2011, 14:607-621

60. Mercurio F, Manning AM: NF-kappaB as a primary regulator of the stress response. Oncogene 1999, 18:6163-6171
61. Morgan MJ, Liu ZG: Crosstalk of reactive oxygen species and NF-kappaB signaling. Cell Res 2011, 21:103-115

62. Wang L, Brugge JS, Janes KA: Intersection of FOXO- and RUNX1mediated gene expression programs in single breast epithelial cells during morphogenesis and tumor progression. Proc Natl Acad Sci U S A 2011, 108:E803-E812

63. Gruosso T, Mieulet V, Cardon M, Bourachot B, Kieffer Y, Devun F, Dubois T, Dutreix M, Vincent-Salomon A, Miller KM, MechtaGrigoriou F: Chronic oxidative stress promotes $\mathrm{H} 2 \mathrm{AX}$ protein degradation and enhances chemosensitivity in breast cancer patients. EMBO Mol Med 2016, 8:527-549

64. Hornsveld M, Smits LM, Meerlo M, van Amersfoort M, Groot Koerkamp MJ, van Leenen D, Kloet DEA, Holstege FCP, Derksen PWB, Burgering BMT, Dansen TB: FOXO transcription factors both suppress and support breast cancer progression. Cancer Res 2018, 78:2356-2369

65. Hornsveld M, Dansen TB, Derksen PW, Burgering BMT: Re-evaluating the role of FOXOs in cancer. Semin Cancer Biol 2017, 50: 90-100

66. Kim HJ, Lee SY, Kim CY, Kim YH, Ju W, Kim SC: Subcellular localization of FOXO3a as a potential biomarker of response to combined treatment with inhibitors of PI3K and autophagy in PIK3CA-mutant cancer cells. Oncotarget 2017, 8:6608-6622

67. Paik JH, Kollipara R, Chu G, Ji H, Xiao Y, Ding Z, Miao L, Tothova Z, Horner JW, Carrasco DR, Jiang S, Gilliland DG, Chin L, Wong WH, Castrillon DH, DePinho RA: FoxOs are lineage-restricted redundant tumor suppressors and regulate endothelial cell homeostasis. Cell 2007, 128:309-323

68. Chandarlapaty S, Sawai A, Scaltriti M, Rodrik-Outmezguine V, Grbovic-Huezo O, Serra V, Majumder PK, Baselga J, Rosen N: AKT inhibition relieves feedback suppression of receptor tyrosine kinase expression and activity. Cancer Cell 2011, 19:58-71

69. Han JM, Patterson SJ, Levings MK: The role of the PI3K signaling pathway in $\mathrm{CD} 4(+) \mathrm{T}$ Cell differentiation and function. Front Immunol 2012, 3:245

70. Yang JY, Zong CS, Xia W, Yamaguchi H, Ding Q, Xie X, Lang JY, Lai CC, Chang CJ, Huang WC, Huang H, Kuo HP, Lee DF, Li LY, Lien $\mathrm{HC}$, Cheng $\mathrm{X}$, Chang $\mathrm{KJ}$, Hsiao CD, Tsai FJ, Tsai $\mathrm{CH}$, Sahin AA, Muller WJ, Mills GB, Yu D, Hortobagyi GN, Hung MC: ERK promotes tumorigenesis by inhibiting FOXO3a via MDM2mediated degradation. Nat Cell Biol 2008, 10:138-148

71. Liu L, Greger J, Shi H, Liu Y, Greshock J, Annan R, Halsey W, Sathe GM, Martin AM, Gilmer TM: Novel mechanism of lapatinib resistance in HER2-positive breast tumor cells: activation of AXL. Cancer Res 2009, 69:6871-6878

72. Chang JT, Carvalho C, Mori S, Bild AH, Gatza ML, Wang Q, Lucas JE, Potti A, Febbo PG, West M, Nevins JR: A genomic strategy to elucidate modules of oncogenic pathway signaling networks. Mol Cell 2009, 34:104-114

73. Kirouac DC, Du JY, Lahdenranta J, Overland R, Yarar D, Paragas V, Pace E, McDonagh CF, Nielsen UB, Onsum MD: Computational modeling of ERBB2-amplified breast cancer identifies combined ErbB2/3 blockade as superior to the combination of MEK and AKT inhibitors. Sci Signal 2013, 6:ra68

74. Vanhaesebroeck B, Stephens L, Hawkins P: PI3K signalling: the path to discovery and understanding. Nat Rev Mol Cell Biol 2012, 13: 195-203

75. van der Horst A, Burgering BM: Stressing the role of FoxO proteins in lifespan and disease. Nat Rev Mol Cell Biol 2007, 8: $440-450$

76. Webb AE, Brunet A: FOXO transcription factors: key regulators of cellular quality control. Trends Biochem Sci 2014, 39:159-169

77. Lin A, Yao J, Zhuang L, Wang D, Han J, Lam EW, Gan B: The FoxO-BNIP3 axis exerts a unique regulation of mTORC1 and cell survival under energy stress. Oncogene 2014, 33:3183-3194

78. Hornsveld M, Dansen TB: The hallmarks of cancer from a redox perspective. Antioxid Redox Signal 2016, 25:300-325 
79. Klotz LO, Sanchez-Ramos C, Prieto-Arroyo I, Urbanek P, Steinbrenner H, Monsalve M: Redox regulation of FoxO transcription factors. Redox Biol 2015, 6:51-72

80. van den Berg MC, van Gogh IJ, Smits AM, van Triest M, Dansen TB, Visscher M, Polderman PE, Vliem MJ, Rehmann H, Burgering BM: The small GTPase RALA controls c-Jun N-terminal kinase-mediated FOXO activation by regulation of a JIP1 scaffold complex. J Biol Chem 2013, 288:21729-21741

81. Coomans de Brachene A, Demoulin JB: FOXO transcription factors in cancer development and therapy. Cell Mol Life Sci 2016, 73: 1159-1172

82. Andre F, Khalil A, Slimane K, Massard C, Mathieu MC, Vignot S, Assi H, Delaloge S, Spielmann M: Mitotic index and benefit of adjuvant anthracycline-based chemotherapy in patients with early breast cancer. J Clin Oncol 2005, 23:2996-3000

83. Nagashima $T$, Shigematsu $N$, Maruki $R$, Urano $Y$, Tanaka $H$, Shimaya A, Shimokawa T, Shibasaki M: Discovery of novel forkhead box $\mathrm{O} 1$ inhibitors for treating type 2 diabetes: improvement of fasting glycemia in diabetic db/db mice. Mol Pharmacol 2010, 78:961-970

84. Kawahara T, Kagaya N, Masuda Y, Doi T, Izumikawa M, Ohta K, Hirao A, Shin-ya K: Foxo3a inhibitors of microbial origin, JBIR-141 and JBIR-142. Org Lett 2015, 17:5476-5479

85. Langlet F, Haeusler RA, Linden D, Ericson E, Norris T, Johansson A, Cook JR, Aizawa K, Wang L, Buettner C, Accili D: Selective inhibition of FOXO1 activator/repressor balance modulates hepatic glucose handling. Cell 2017, 171:824-835.e18 